Research article

\title{
An investigation of polymorphisms in the I 7q I I.2-I 2 CC chemokine gene cluster for association with multiple sclerosis in
} Australians

\author{
Matthew J Bugeja1, David Booth11, Bruce Bennetts²,3, Robert Heard1, \\ Justin Rubio ${ }^{4}$ and Graeme Stewart*1
}

\begin{abstract}
Address: ${ }^{T}$ The Institute for Immunology and Allergy Research, Westmead Millennium Institute, Westmead Campus, University of Sydney, Westmead, NSW 2145, Australia, ${ }^{2}$ Department of Molecular Genetics, The Children's Hospital at Westmead, University of Sydney, Westmead, NSW 2145, Australia, ${ }^{3}$ Discipline of Paediatrics and Child Health, University of Sydney, NSW 2006, Australia and ${ }^{4}$ The Howard Florey Institute and the Southern MS Genetics Consortium, University of Melbourne, Parkville, Victoria 3052, Australia

Email: Matthew J Bugeja - mbugeja@med.usyd.edu.au; David Booth - davidb@westgate.wh.usyd.edu.au; Bruce Bennetts - BruceB@chw.edu.au; Robert Heard - heard@idx.com.au; Justin Rubio - j.rubio@hfi.unimelb.edu.au; Graeme Stewart* - stewartg@westgate.wh.usyd.edu.au

* Corresponding author
\end{abstract}

Published: 26 July 2006

BMC Medical Genetics 2006, 7:64 doi:10.1 186/147I-2350-7-64

This article is available from: http://www.biomedcentral.com/147I-2350/7/64

(C) 2006 Bugeja et al; licensee BioMed Central Ltd.

This is an Open Access article distributed under the terms of the Creative Commons Attribution License (http://creativecommons.org/licenses/by/2.0), which permits unrestricted use, distribution, and reproduction in any medium, provided the original work is properly cited.

\begin{abstract}
Background: Multiple sclerosis (MS) is a disorder of the central nervous system (CNS) characterised by inflammation and neuronal degeneration. It is believed to result from the complex interaction of a number of genes, each with modest effect. Chemokines are vital to the migration of cells to sites of inflammation, including the CNS, and many are implicated in MS pathogenesis. Most of the CC chemokine genes are encoded in a cluster on chromosome 17qII.2-12, which has been identified in a number of genome wide screens as being potentially associated with MS.

Methods: We conducted a two-stage analysis to investigate the chemokine gene cluster for association with MS. After sequencing the chemokine genes in several DNA pools to identify common polymorphisms, 12 candidate single-nucleotide polymorphisms (SNPs) were genotyped in a cohort of Australian MS trio families.

Results: Marginally significant (uncorrected) transmission distortion was identified for four of the SNPs after stratification for several factors. We also identified marginally significant (uncorrected) transmission distortion for haplotypes encompassing the CCL2 and CCLII genes, using two independent cohorts, which was consistent with recent reports from another group.

Conclusion: Our results implicate several chemokines as possibly being associated with MS susceptibility, and given that chemokines and their receptors are suitable targets for therapeutic agents, further investigation is warranted in this region.
\end{abstract}

\section{Background}

Multiple sclerosis (MS) is the most common chronic neurological disease in young adults. It is characterised by inflammation of the central nervous system (CNS), believed to be the result of an autoimmune reaction resulting in demyelination and destruction of neural supporting cells [1]. Epidemiological studies suggest a multifactorial aetiology for MS, implicating a complex interplay 
between environmental and genetic factors [2]. In the past ten years, a large number of genome wide screens have been conducted, including the recent GAMES collaboration (Genetic Analysis of Multiple sclerosis in EuropeanS) [3]. Multiple regions of potential linkage and association with MS have been identified, suggesting that genetic predisposition to MS might result from the modest contribution of many genetic factors, which, if identified, may present important new therapeutic targets [4].

The inflammatory response that is characteristic of MS requires the targetted migration of leukocytes into the CNS, which is under the control of chemokines. Over 40 members of the human chemokine family have been identified, which act upon a variety of leukocytes via interactions with almost 20 seven-transmembrane domain chemokine receptors [5]. Chemokines are small molecules of approximately $8-10 \mathrm{kDa}$ in size, and are primarily classified on the basis of the relative positioning of two conserved cysteines. In the $\mathrm{CC}$ chemokines, the two cysteines are adjacent, and in the CXC chemokines, a single amino acid residue separates the cysteines. Two smaller subgroups have also been identified; the $\mathrm{CX}_{3} \mathrm{C}$ chemokines, and the $\mathrm{C}$ chemokines.

Functionally, CC chemokines chemoattract a wide range of cells, including lymphocytes, dendritic cells, monocytes and some granulocytes [6,7], whilst CXC chemokines are chemoattractant for neutrophils and lymphocytes $[6,7]$. There is increasing evidence for chemokines possessing abilities beyond that of migration, including $\mathrm{T}$ helper cell subset differentiation [8], T cell costimulation $[9,10]$, and macrophage and natural killer cell maturation $[11,12]$.

Substantial evidence supports the involvement of CC chemokines in the pathogenesis of MS. In the mouse model of MS, experimental autoimmune encephalomyelitis (EAE), knockout of CCL2 leads to resistance to disease induction [13], whilst CCL3, CCL4 and CCL5 have all been implicated in EAE development [14,15]. However, CCL3-knockout mice were found to be fully susceptible to myelin oligodendrocyte glycoprotein (MOG)induced EAE [16]. In MS lesions, expression of CC chemokines, including CCL2, CCL3, CCL4, CCL5, CCL7 and CCL8, and their receptors, have been identified on a wide variety of cells, such as astrocytes, microglia and perivascular $T$ cells [17-22]. In addition, altered levels of CC chemokines and receptors have been identified in the serum and cerebrospinal fluid (CSF) of MS patients; some are elevated (including CCL5), whilst CCL2 is decreased in the CSF [22-26], possibly due to removal by CCR2-positive migrating cells as they cross the blood-brain barrier [27].

Fourteen of the $28 \mathrm{CC}$ chemokine genes are clustered on chromosome 17q11.2-12 (Figure 1) [28]. This cluster spans slightly less than $2 \mathrm{Mb}$, and is split into two subclusters separated by a gap of $1.5 \mathrm{Mb}$. The $17 \mathrm{q} 11.2-12$ region has been implicated in genome-wide screens for linkage and association with MS [29-34], and in a metaanalysis of three genome screens, the most significant nonparametric linkage score was obtained for this region [35]. The $17 \mathrm{q}$ region is also syntenic to an EAE quantitative trait locus on chromosome 10, which includes a chemokine gene cluster [36], and non-synonymous polymorphisms in murine CCL1, CCL2 and CCL12 were identified as candidates for the eae7 quantitative trait locus [37].

Candidate gene studies of CC chemokines in MS have not been extensive. Rather, the majority of studies have focussed on other diseases. Polymorphisms from several CC chemokine genes have been variably associated with diseases such as tuberculosis [38], HIV [39], arthritis [40], and asthma and atopy [41,42]. The CCR5 $\Delta 32$ mutation has been widely studied in MS. Whilst it was found not to be a general susceptibility factor for MS [43], it may have effects on age of onset or disease progression $[44,45]$. More recently, several moderate single-loci and haplo-

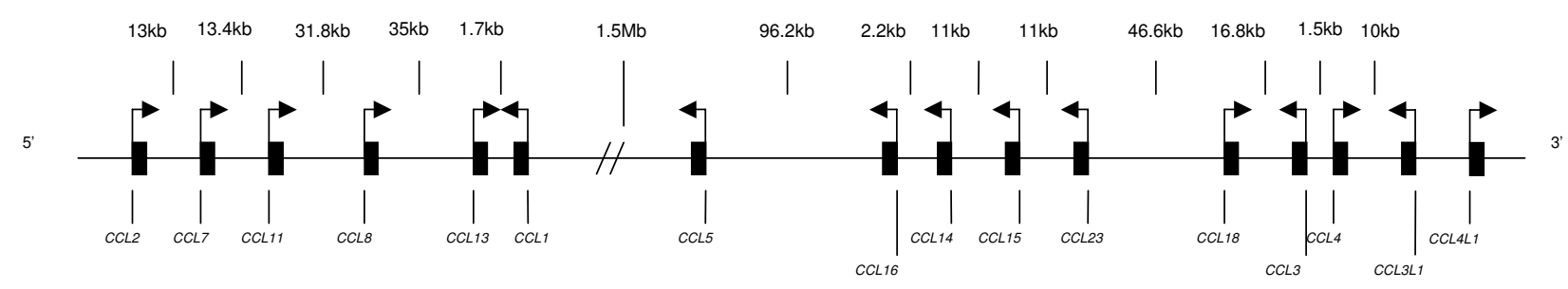

Figure I

Schematic representation of the I7qII.2-I2 CC chemokine gene cluster (not to scale). 
typic associations with MS were identified for single nucleotide polymorphisms (SNPs) from the CC chemokine gene cluster [46].

It was the aim of our study to conduct candidate gene analyses for the CC chemokines in order to identify polymorphisms and/or haplotypes associated with MS. We undertook a two-stage analysis. The first stage involved the scanning of the genes for published (online) and novel polymorphisms in several DNA pools by DNA sequencing. From these, 12 candidate SNPs were then individually genotyped in a cohort of MS trio families in the second stage. We also sought confirmation of our findings in an independent cohort of Australian MS families. Marginally significant (uncorrected) transmission distortion was identified for four of the SNPs, as well as for haplotypes encompassing the CCL2 and CCL11 genes.

\section{Methods \\ Subjects}

For the main study, all sporadic MS cases and parents (including 373 MS trio families) were recruited by our facility at the Institute for Immunology and Allergy Research, Westmead Hospital (Australia). The familial DNA pool was derived from MS probands from multicase families obtained from the National Register of Multiple Sclerosis Families (Rex Simmons, Canberra Hospital, Australia). Control individuals were composed of local staff members and spouses of sporadic MS cases. MS patients and controls had the same ethnic composition, and were of similar average age (patients $=50 y o$; controls = 52.8yo). $90 \%$ of MS patients were of northern European origin, while the remainder were of southern European origin. The ratio of female to male patients was $4: 1$; the control ratio was $1.5: 1$. Approximately $60 \%$ of $\mathrm{MS}$ patients were HLA-DRB $1 * 1501$ positive; $73 \%$ had relapsing-remitting (RR)-MS, 20\% secondary-progressive (SP)$\mathrm{MS}, 5 \%$ primary-progressive (PP)-MS, and $2 \%$ progressive relapsing (PR)-MS. An additional cohort of 208 Australian MS trio families was obtained from the Southern MS Genetics Consortium for independent validation of our initial results. All cases were verified as having MS as defined by the Poser criteria [47], and provided written informed

consent.

\section{Pooled DNA sequencing}

DNA was extracted from whole blood using a rapid salting out method [48]. Methods for the construction of the DNA pools has been described elsewhere [49]. Four DNA pools were constructed: 217 HLA-DRB $1 * 1501$ positive sporadic MS patients; 155 HLA-DRB1 * 1501 negative sporadic MS patients; 169 MS probands from multicase families; 185 unrelated, unaffected controls. HLADRB1*1501 status was genotyped using a SYBR Green assay (Applied Biosystems (ABI)), described elsewhere [50].

DNA sequencing primers were designed to encompass the exons of all genes analysed, as well as segments of the putative promoter region, and often part of the 3' untranslated region (UTR) (see additional file 1: 17qSuppTable1). Where possible, primers were also designed to maximise coverage of published SNPs, which were identified from online SNP databases.

DNA sequencing of the chemokine genes was performed on each of the DNA pools and a single individual, included for SNP allele frequency correction purposes and for potential identification of rare SNPs. PCR products for each gene segment were amplified using the ABI $2 \times$ PCR Master Mix, with 50 ng of genomic DNA and appropriate amplification primer pairs (Sigma Genosys) to a final concentration of $5 \mathrm{ng} / \mu \mathrm{L}$. PCR reactions followed a standard PCR program: 1 cycle of $95^{\circ} \mathrm{C}$ for 10 minutes; 35 cycles of $94^{\circ} \mathrm{C}$ for 30 seconds, $62^{\circ} \mathrm{C}$ for 30 seconds, and $72^{\circ} \mathrm{C}$ for 1 minute and 10 seconds; a final elongation step of $72^{\circ} \mathrm{C}$ for 10 minutes. PCR products were purified from the PCR cocktail by use of either the QIAQuick ${ }^{\circledast}$ PCR purification kit (QIAGEN), or ExoSAP-IT (USB Corporation). Sequencing reactions were performed using the ABI Big Dye ${ }^{\circledast}$ Terminator v3.1 Cycle Sequencing Kit. Final samples were sequenced using an $\mathrm{ABI} 3100$ sequence analyser. Sequences were viewed using the ABI PRISM ${ }^{\mathrm{TM}}$ EditView software.

\section{Genotyping in Trio Families \\ SNaPshot}

An initial set of seven CC chemokine gene SNPs were selected for individual genotyping in a cohort of $204 \mathrm{MS}$ trio families (Table 1): CCL2 -2581, CCL2 -2138, CCL11 67, CCL5 -471, CCL15 -1284, CCL15 136+88 and CCL23 -289. These SNPs were genotyped using the SNaPshot assay, which allows the genotyping of multiple SNPs simultaneously in a single-tube multiplexed reaction, using primer-extension methodology [51] (see additional file 3: 17qSuppTable3 for SNaPshot primer details for each of the seven SNPs).

SNaPshot genotyping was performed on the pooled PCR products of each individual, amplified using either the ABI $2 \times$ PCR master mix, or the Fermentas $2 \times$ PCR master mix (Progen). SNaPshot reactions were optimised in individuals of known genotype. Between 100-200 ng of DNA was used from each individual with the appropriate amplification primer pair (Sigma Genosys) to a final concentration of $5 \mathrm{ng} / \mu \mathrm{L}$. PCR products were amplified using the standard conditions, as described above. The successful amplification of PCR products was verified on $1 \%$ agarose gels. The PCR products for each individual were then 
Table I: Summary of SNPs identified by sequencing of CC chemokine genes in DNA pools that were selected for individual genotyping. Other detected SNPs are described in Supplementary Table 2.

\begin{tabular}{|c|c|c|c|c|c|}
\hline \multirow[b]{2}{*}{ Locus } & \multirow[b]{2}{*}{ rsID } & \multirow{2}{*}{$\begin{array}{c}\begin{array}{c}\text { Estimated } \\
\text { minor allele } \\
\text { frequency }\end{array} \\
\text { Control pool }\end{array}$} & \multicolumn{3}{|c|}{$\begin{array}{c}\text { Estimated relative risk } \\
\text { (for minor allele frequency }>0.15 \text { ) }\end{array}$} \\
\hline & & & $\begin{array}{l}\text { HLA-DRB I } *|50| \\
\text { positive pool }\end{array}$ & $\begin{array}{l}\text { HLA-DRB I } *|50| \\
\text { negative pool }\end{array}$ & Familial pool \\
\hline \multicolumn{6}{|l|}{ CCL2 } \\
\hline$-258 \mid A>G$ & | $0246 \mid$ | & 0.5 & 0.9 & 0.8 & 0.7 \\
\hline$-2138 A>T$ & 1024610 & 0.3 & 1.2 & 1.5 & 1.5 \\
\hline \multicolumn{6}{|l|}{ CCLII } \\
\hline$-488 C>A$ & $|773596|$ & 0.2 & 1.2 & 1.2 & 1.3 \\
\hline $67 \mathrm{G}>\mathrm{A}(\mathrm{A}>\mathrm{T})^{+}$ & 3744508 & 0.1 & - & - & - \\
\hline \multicolumn{6}{|l|}{ CCL8 } \\
\hline$-572 C>T$ & 3138035 & 0.3 & I.I & 1.0 & 1.2 \\
\hline$\dagger 205 \mathrm{~A}>\mathrm{C}(\mathrm{K}>\mathrm{Q})^{+}$ & 3138038 & 0.2 & 0.8 & 0.8 & 0.7 \\
\hline \multicolumn{6}{|l|}{$\operatorname{CCL5}(-)$} \\
\hline$-47 \mid C>T$ & 2107538 & 0.2 & 1.2 & 1.3 & 1.1 \\
\hline \multicolumn{6}{|l|}{ CCLI $6(-)$} \\
\hline$-595 C>A$ & 854680 & 0.1 & - & - & - \\
\hline \multicolumn{6}{|l|}{ CCLI4 (-) } \\
\hline$-649 T>A$ & 854682 & $0.2 *$ & $1.1 *$ & $1.0 *$ & $1.4^{*}$ \\
\hline \multicolumn{6}{|l|}{ CCLI 5 (-) } \\
\hline$-1284 A>C$ & 854628 & $<0.1$ & - & Undetectable & - \\
\hline $136+88 C>T$ & Novel & 0.3 & 0.8 & 0.6 & 0.5 \\
\hline \multicolumn{6}{|l|}{$\operatorname{CCL23~(-)~}$} \\
\hline$-289 A>C$ & 854655 & $0.2 *$ & $0.7 *$ & $0.5 *$ & $1.0 *$ \\
\hline $316 \mathrm{~T}>\mathrm{C}(\mathrm{M}>\mathrm{V})+$ & 1003645 & $0.2 *$ & $1.0 *$ & $0.7 *$ & $1.0 *$ \\
\hline
\end{tabular}

All SNPs classified relative to translation start site. Relative risks determined relative to control pool. SNPs in bold were individually genotyped in second stage

(-) Gene encoded in anti-sense direction; SNPs reclassified to account for this

+ Coding change in brackets

tThe CCL8 205 SNP was originally selected for genotyping by SNPLEX ${ }^{\mathrm{TM}}$, but failed the SNPLEX ${ }^{\mathrm{TM}}$ algorithm, and was replaced with the CCL8 -

572 SNP

* Heterozygous individual correction applied

rsID: SNP identification number

pooled, and an aliquot purified using ExoSAP-IT (USB Corporation). To this aliquot was then added $2.5 \mu \mathrm{L}$ of SNaPshot Multiplex reagent (ABI), and pooled SNaPshot primers as defined in Supplementary Table 3, and the $\mathrm{SNaPshot}$ procedure was followed as per the manufacturer's instructions (ABI). Samples were then scanned using an ABI 3100. SNaPshot results were viewed using the GeneScan ${ }^{\mathrm{TM}}$ software (ABI) and genotypes determined using the GeneMapper ${ }^{\mathrm{TM}}$ software package (ABI).

\section{SNPlex ${ }^{\mathrm{TM}}$}

An additional five CC chemokine gene SNPs were selected for genotyping in the full cohort of 373 MS trio families (Table 1): CCL11 -488, CCL8 205, CCL16 -595, CCL14 649 and CCL23 316. These SNPs were genotyped using the SNPlex ${ }^{\mathrm{TM}}$ genotyping system (ABI), for which SUPAMAC (University of Sydney, Australia) were contracted. This system allows high-throughput genotyping of up to 48 SNPs simultaneously in a single tube using an oligonucleotide ligation assay. Initially, candidate SNP details were submitted, after which suitability for the assay was determined by running the SNPs through an algorithm. Oligonucleotides were then designed for each SNP, and applied to the DNA samples (500 ng genomic DNA). Samples were scanned using an ABI 3730. Genotyping results were determined using the GeneMapper ${ }^{\mathrm{TM}}$ software package (ABI), utilising an allelic discrimination cluster analysis to allocate genotype calls with maximum stringency.

\section{Additional genotyping of validation cohort}

Genotyping of the additional cohort of MS trio families was contracted to the Australian Genome Research Facility (AGRF; Brisbane, Australia). Only the CCL2 -2138A>T and CCL11 -488C>A SNPs were genotyped using the Sequenom Autoflex Mass Spectrometer. After submission of SNP details, PCR oligonucleotides were designed and applied to the DNA samples. 


\section{Analyses \& statistics}

Sequencing results from DNA pools and individuals were compared and scanned for published SNPs and novel polymorphisms. All SNPs were classified according to the nomenclature recommended by den Dunnen and Antonarakis [52], and are relative to the translation start site. For genes transcribed in the anti-sense direction (indicated in Table 1 with (-)), the complementary nucleotide for each allele was used, and is used throughout this manuscript. Minor allele frequencies (MAF) of SNPs were estimated by comparing the relative peak heights of the alleles. Where the individual was heterozygous for a particular SNP, the MAF in the DNA pools could be corrected for SNP-specific variation in peak-height intensity. The significance of differences between the MS patient pools and the control pool was measured by estimated relative risk (ERR) calculations.

Each SNP was analysed for transmission distortion within the trios using the transmission disequilibrium test (TDT) [53]. Analysis was performed using the GENEHUNTER program [54].

The HelixTree genetics analysis software (Golden Helix Inc, Bozeman, USA) was used to calculate linkage disequilibrium (LD) for the 12 SNPs analysed and to determine haplotypes in parents only. By using the Expectation/Maximisation (EM) algorithm, the software was able to calculate probabilities of each haplotype occurring, based on multi-locus genotypes. It calculated $D^{\prime}$ and $\mathrm{r}^{2}$ values, which are accepted measures of $\mathrm{LD}$, and performed a $\chi^{2}$ comparison for each pair of SNPs. HaploBlockFinder [55] was used to establish the haplotype block structure across the CC chemokine gene cluster.

TRANSMIT [56] was then used to analyse for haplotype transmission disequilibrium, estimating $\chi^{2}$ values for individual haplotypes, as well as global $\chi^{2}$ values for all haplotypes analysed. Mendelian transmission was checked using MERLIN [57].

\section{Results \\ Identification and analysis of SNPs in CC chemokine genes by DNA pool sequencing}

The CC chemokine genes were scanned using DNA pool sequencing in order to identify common polymorphisms in the region, including the potential identification of novel SNPs, and to establish whether associations might exist for these SNPs. In all, 50 SNPs were identified across the CC chemokine gene cluster (a list of all variants identified is available in the additional file 2: 17qSuppTable2), 48 of which were known; novel SNPs were detected in CCL8 and CCL15. Five common SNPs within exons were confirmed, four of which cause codon changes. Twenty-nine SNPs had MAF $>0.15$ in the control pool, designated as 'common' here, and for which we had statistical power to detect associations for ERR $>1.5$.

The greater than 90\% DNA sequence homology between CCL3 and CCL3L1, and between CCL4 and CCL4L1, made it impractical to design specific primers for each of these genes. Thus, these four genes were not sequenced.

\section{Population genetics of individually genotyped markers}

Based on their likely functional significance (codon changing, putative promoter region, reported functional significance) and ERR from the pooled DNA sequencing, 12 SNPs were chosen for genotyping in the MS cohort, either by SNaPshot or SNPlex ${ }^{\mathrm{TM}}$ (Table 1). The CCL8 205 SNP was originally chosen for analysis by $\mathrm{SNPlex}^{\mathrm{TM}}$, but failed to pass the SNPlex ${ }^{\mathrm{TM}}$ algorithm. Thus, it was replaced with the CCL8 -572 SNP, which is in LD with the original SNP (International HapMap Project [58]).

Genotype information retrieval for the seven SNPs genotyped using SNaPshot was 100\%. Genotype information available for single-locus analysis for the five SNPs genotyped by SNPlex ${ }^{\mathrm{TM}}$ ranged between $84-87 \%$; losses due to failed genotyping, and the exclusion of genotypes called with low stringency. The SNPlex ${ }^{\mathrm{TM}}$ genotyping, which is based on a highly multiplex PCR, was quite sensitive to DNA quality. Unambiguous genotypes could be determined using the SNPlex ${ }^{\mathrm{TM}}$ calling algorithm, which we have used at the highest stringency. The genotype frequencies for all SNPs conformed to Hardy-Weinberg equilibrium estimates, except for the CCL11 -488 SNP in mothers. The Mendelian error rate for the seven SNPs was $\leq 2 \%$. Table 2 lists the MAF of the 12 markers as determined by individual genotyping.

\section{Linkage disequilibrium and haplotypes}

The HelixTree genetics analysis software (Golden Helix Inc, Bozeman, USA) was used to conduct a pair-wise analysis of LD across the $12 \mathrm{CC}$ chemokine gene markers, using the parents only. This software calculated both $\mathrm{D}^{\prime}$ and $\mathrm{r}^{2}$ measures of LD, and the data are represented in Figure 2. These results were confirmed using the Haploview software package [59]. Results suggest a clear separation of the SNPs into two haplotype blocks of moderate to strong LD, confirmed by HaploBlockFinder [55] (represented in Figure 2). The first block extended from the CCL2 -2581 SNP to the CCL11 67 SNP; a distance of $33.1 \mathrm{~kb}$. The second block extended from the CCL14 -649 SNP to the CCL23 -289 SNP, but did not include the CCL15 136+88 SNP, which interestingly was not in LD with any of its neighbouring SNPs. This block extended across $30.9 \mathrm{~kb}$.

The HelixTree software was then used to construct haplotypes only across the two clear haplotype blocks, in parents only (350-650 individuals; actual numbers varied 


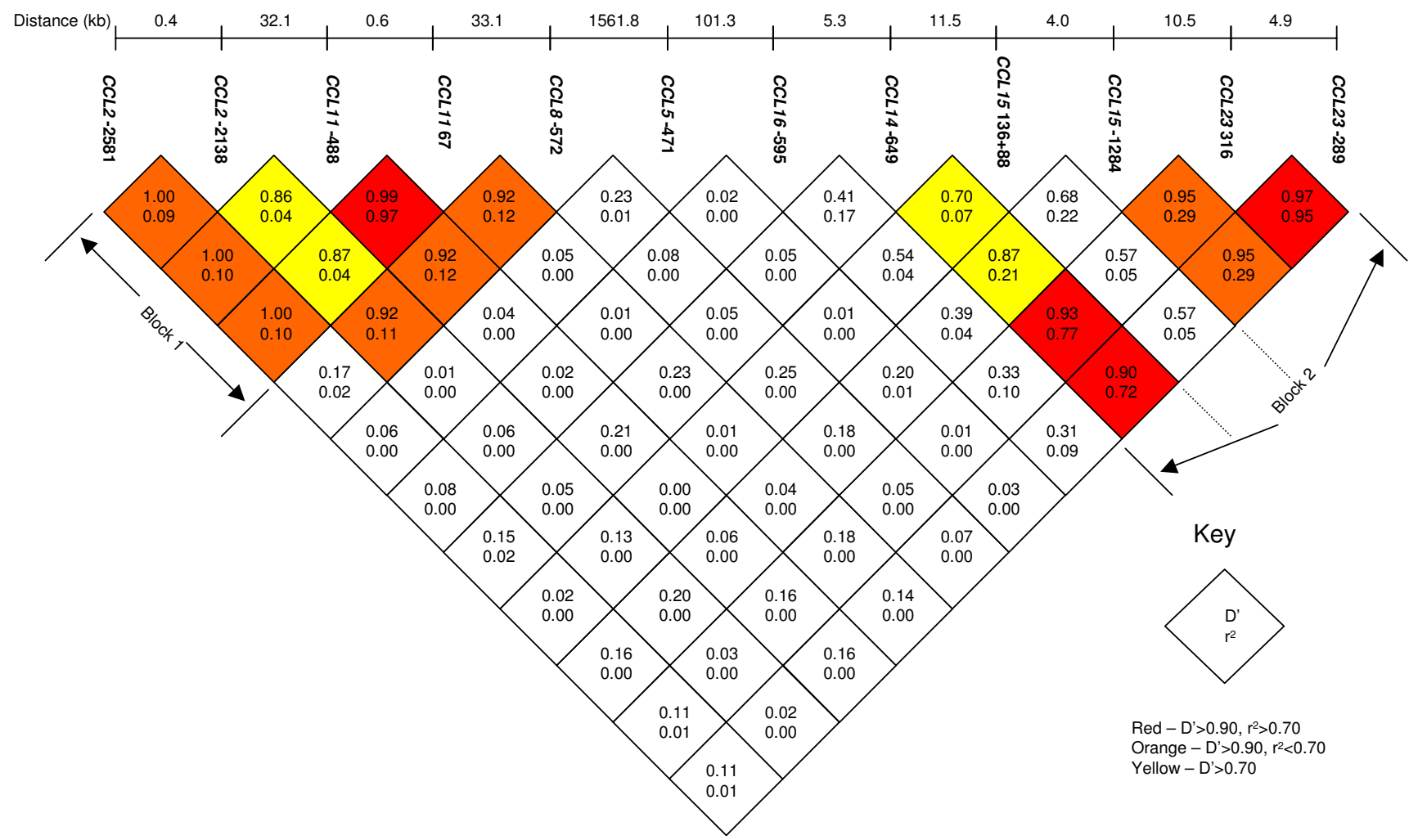

Figure 2

LD plot of CC chemokine gene cluster SNPs.

for each SNP); and to estimate haplotype frequencies. Table 2 lists the common haplotypes (frequency >0.05) across the two haplotype blocks and their frequencies within the unaffected parents. Four common haplotypes were identified in the 5 ' haplotype block, with frequencies between 0.18 and 0.33 . In the 3 ' haplotype block, three common haplotypes were identified, but the TATA haplotype was the most common by a substantial margin (frequency $=0.76)$.

\section{Analysis for transmission distortion across single markers and haplotypes}

Single-locus transmission disequilibrium

Analyses for transmission distortion were undertaken for the 12 chemokine gene markers in all of the trios, as well as subgroups stratified based on HLA-DRB1*1501 status, disease course and gender. Results are listed in Table 3.

No significant transmission distortion was found for any of the SNPs when analysed in all individuals. Upon stratification, a trend towards excess transmission of the CCL5 $-471 \mathrm{~T}$ allele was found in the HLA-DRB $1 * 1501$ negative group $(\mathrm{P}$ (uncorrected $)=0.03)$. Interestingly, DNA sequencing had also suggested an increased ERR for the T allele in the HLA-DRB $1 * 1501$ negative pool. For the
CCL14 -649T>A SNP, transmission distortion of the T allele was found in patients with RR-MS ( $\mathrm{P}$ (uncorrected) $=0.03)$. In contrast, transmission distortion of the A allele was found in SP-MS patients $(\mathrm{P}($ uncorrected $)=0.02)$. Transmission distortion in SP-MS patients was also found for the CCL23 316C allele $(\mathrm{P}$ (uncorrected $)=0.02)$. For the CCL23 -289A>C SNP, transmission distortion of the C allele was found in male MS patients ( $\mathrm{P}$ (uncorrected) = $0.03)$. This distortion was accentuated in male patients with SP-MS (P(uncorrected $)=0.007)$, however this result was inconclusive given the small number of individuals in this group ( $\mathrm{n}=10$ informative transmissions). None of these results would survive a conservative Bonferroni correction for multiple comparisons.

\section{Haplotype TDT}

Whilst single-locus analyses did not suggest that any of the SNPs were significantly associated with MS susceptibility, it is conceivable that they may define MS-associated haplotypes. Using the TRANSMIT [56] software, haplotype transmission was evaluated for common haplotypes ( $>5 \%$ frequency) of decreasing size from either block, as well as pairwise analyses across all twelve SNPs. Analyses were conducted only where genotyping information was available for all individuals across all 12 SNPs $(n=162$ 
Table 2: Common haplotype and minor allele frequencies for SNPs within haplotype blocks in unaffected parents $(n=350-650$ individuals), determined by individual genotyping.

\begin{tabular}{|c|c|c|c|c|}
\hline \multicolumn{5}{|l|}{ (a) 5' block } \\
\hline$C C L 2-258 \mid A>G$ & $C C L 2-2 \mid 38 A>T$ & $C C L I I-488 C>A$ & $C C L I / 67 G>A$ & Haplotype Frequency \\
\hline \multicolumn{5}{|l|}{ Haplotypes } \\
\hline$A$ & A & C & G & 0.33 \\
\hline G & $A$ & $\mathrm{C}$ & G & 0.29 \\
\hline$A$ & A & $A$ & A & 0.19 \\
\hline A & $\mathrm{T}$ & $\mathrm{C}$ & G & 0.18 \\
\hline \multicolumn{5}{|l|}{ Minor allele frequency } \\
\hline G & $T$ & A & A & \\
\hline 0.29 & 0.19 & 0.19 & 0.20 & \\
\hline \multicolumn{5}{|l|}{ (b) 3' block } \\
\hline CCLI $4-649 T>A$ & $C C L I 5-1284 A>C$ & $C C L 23316 \mathrm{~T}>\mathrm{C}$ & $C C L 23-289 A>C$ & Haplotype Frequency \\
\hline \multicolumn{5}{|l|}{ Haplotypes } \\
\hline $\mathrm{T}$ & A & $\mathrm{T}$ & A & 0.76 \\
\hline$A$ & A & $\mathrm{C}$ & C & 0.12 \\
\hline A & C & C & C & 0.07 \\
\hline \multicolumn{5}{|l|}{ Minor allele frequency } \\
\hline $\mathrm{A}$ & $\mathrm{C}$ & $\mathrm{C}$ & $\mathrm{C}$ & \\
\hline 0.23 & 0.08 & 0.20 & 0.20 & \\
\hline \multicolumn{5}{|c|}{$\begin{array}{l}\text { (c) Minor allele frequencies } \\
\text { of remaining SNPs }\end{array}$} \\
\hline SNP & Minor allele frequency & & & \\
\hline CCL8 $-572 C>T$ & Т 0.37 & & & \\
\hline$C C L 5-47 \mid C>T$ & Т 0.19 & & & \\
\hline$C C L I 6-595 C>A$ & A 0.22 & & & \\
\hline$C C L / 5 \mid 36+88 C>T$ & Т 0.05 & & & \\
\hline
\end{tabular}

families), with additional trio families removed after identification of Mendelian inconsistencies.

Table 4 lists common haplotypes for which transmission distortion was identified. All of these findings were identified within the 5' haplotype block (CCL2 -2581.CCL2 2138.CCL11 -488.CCL11 67). Marginally significant transmission distortion was found for two four-marker haplotypes, and several three-marker haplotypes $(\mathrm{P} \leq$ $0.05)$. Marginally significant transmission distortion was also identified for pairwise analyses for CCL2 -2581.CCL2 $-2138(\mathrm{P}($ uncorrected $)=0.05)$ and CCL2 -2138.CCL11 488 haplotypes $(\mathrm{P}($ uncorrected $)=0.04)$. No significant transmission distortion was found for haplotypes across the 3 ' haplotype block.

Verification of haplotype results in an independent cohort Independent validation of the results discussed above was sought in an independent cohort of 208 Australian MS trio families obtained from the Southern MS Genetics
Consortium. It was determined that genotyping the CCL2 $-2138 \mathrm{~A}>\mathrm{T}$ and CCL11 -488C>A SNPs was sufficient for information extraction across the four markers within the 5' haplotype block.

Genotype and minor allele frequencies for both SNPs were equivalent to those obtained for our cohort, and were in Hardy-Weinberg equilibrium. LD properties between the two markers were also in agreement with our results. No evidence for single-locus transmission distortion was identified for either SNP, supporting our original findings. Full haplotype transmission data could be obtained for 169 trios; losses were due to genotyping failure for either SNP. Two-marker haplotype analysis revealed slight transmission distortion for the A.C and T.C haplotypes in the same direction as our original findings, but the distortion was not significant (Table 4(b)). However, combining the total datasets of the two cohorts restored the original trends for transmission distortion for the A.C and T.C haplotypes ( $\mathrm{P}=0.05)$ (Table 4(c)). 
Table 3: Single locus TDT analysis of individually genotyped CC chemokine gene markers.

\begin{tabular}{|c|c|c|c|c|c|c|c|c|c|c|c|c|c|c|}
\hline \multirow[t]{2}{*}{ Locus } & \multicolumn{2}{|c|}{ All families } & \multicolumn{2}{|c|}{$\begin{array}{c}\text { HLA- } \\
\text { DRBI*I50I } \\
\text { positive }\end{array}$} & \multicolumn{2}{|c|}{$\begin{array}{c}\text { HLA- } \\
\text { DRBI*I50I } \\
\text { negative }\end{array}$} & \multicolumn{2}{|c|}{ RR-MS } & \multicolumn{2}{|c|}{ SP-MS } & \multicolumn{2}{|c|}{ Male } & \multicolumn{2}{|c|}{ Female } \\
\hline & $\mathrm{T}: \mathrm{N}$ & $P$ & $\mathrm{~T}: \mathrm{N}$ & $P$ & $\mathrm{~T}: \mathrm{N}$ & $P$ & $\mathrm{~T}: \mathrm{N}$ & $P$ & $\mathrm{~T}: \mathrm{N}$ & $P$ & $\mathrm{~T}: \mathrm{N}$ & $P$ & $\mathrm{~T}: \mathrm{N}$ & $P$ \\
\hline${ }^{*} C C L 2-258 \mid A>G$ & $79: 89$ & 0.4 & $48: 57$ & 0.4 & $31: 32$ & 0.9 & $51: 68$ & 0.1 & $21: 16$ & 0.4 & $16: 13$ & 0.60 & $63: 76$ & 0.3 \\
\hline${ }^{*} C C L 2-2138 \mathrm{~A}>\mathrm{T}$ & $56: 75$ & 0.1 & $35: 41$ & 0.5 & $21: 34$ & 0.08 & $41: 56$ & 0.1 & $12: 15$ & 0.6 & $13: 13$ & 1 & $43: 62$ & 0.06 \\
\hline$C C L I I-488 C>A$ & $88: 96$ & 0.6 & $45: 59$ & 0.2 & $43: 37$ & 0.5 & $68: 69$ & 0.9 & $15: 17$ & 0.7 & $20: 22$ & 0.8 & $68: 74$ & 0.6 \\
\hline$* C C L I / 67 G>A$ & $71: 65$ & 0.6 & $39: 37$ & 0.8 & $32: 28$ & 0.6 & $54: 46$ & 0.4 & $14: 13$ & 0.8 & $15: 15$ & 1 & $56: 50$ & 0.6 \\
\hline CCL8 $-572 C>T$ & $143: 127$ & 0.3 & $84: 78$ & 0.6 & $59: 49$ & 0.3 & 107:96 & 0.4 & $23: 22$ & 0.9 & $28: 32$ & 0.6 & $115: 95$ & 0.2 \\
\hline${ }^{*} C C L 5-47 \mid C>T$ & $64: 70$ & 0.6 & $45: 35$ & 0.3 & 19:35 & 0.03 & $47: 50$ & 0.8 & $14: 13$ & 0.9 & $14: 18$ & 0.5 & $50: 52$ & 0.8 \\
\hline CCLI6 -595C>A & 103:9| & 0.4 & $58: 53$ & 0.6 & $45: 38$ & 0.4 & $76: 66$ & 0.4 & $14: 19$ & 0.4 & 19:19 & 1 & $84: 72$ & 0.3 \\
\hline CCLI 4 -649T>A & $100: 88$ & 0.4 & $64: 49$ & 0.2 & $36: 39$ & 0.7 & $81: 56$ & 0.03 & $9: 22$ & 0.02 & $|7: 2|$ & 0.5 & $83: 67$ & 0.2 \\
\hline${ }^{*} C C L / 5 \quad 136+88 C>T$ & $18: 10$ & 0.1 & $11: 6$ & 0.2 & $7: 4$ & 0.4 & $15: 6$ & 0.05 & $2: 3$ & 0.7 & $2: 3$ & 0.7 & $16: 7$ & 0.06 \\
\hline$* C C L 15-1284 A>C$ & $29: 27$ & 0.8 & $21: 20$ & 0.9 & $8: 7$ & 0.8 & $25: 17$ & 0.2 & $2: 5$ & 0.3 & $3: 6$ & 0.3 & $26: 21$ & 0.5 \\
\hline$C C L 23316 T>C$ & $85: 90$ & 0.7 & $54: 57$ & 0.8 & $31: 33$ & 0.8 & $70: 58$ & 0.3 & $8: 21$ & 0.02 & 13:22 & 0.1 & $72: 68$ & 0.7 \\
\hline${ }^{*} C C L 23-289 A>C$ & 62:71 & 0.4 & $42: 42$ & 1 & $20: 29$ & 0.2 & $51: 46$ & 0.6 & $9: 17$ & 0.1 & $8: 19$ & 0.03 & $54: 52$ & 0.9 \\
\hline
\end{tabular}

$\mathrm{T}: \mathrm{N}=$ Transmitted:Non-transmitted for major allele

*Markers genotyped using SNaPshot in 204 trio families; HLA-DRBI*I50 I positive: I 23 trio families; HLA-DRB I*I50 I negative: 8I trio families; RR-MS: 147 trio families; SP-MS: 42 trio families; Male: 38 trio families; Female: 166 trio families Remaining markers genotyped using SNPlex ${ }^{\mathrm{TM}}$; All families: 269-296 trio families; HLA-DRBI*I50I positive: I56-I76 trio families; HLA-DRBI*I50I negative: II3-I20 trio families; RR-MS: I93-2।8 trio families; SP-MS: 52-56 trio families; Male: 53-60 trio families; Female: $216-236$ trio families. Significant $P$ values in bold. $P$ values are not corrected for multiple comparisons.

\section{Discussion}

In this study, we have analysed the members of the CC chemokine gene cluster for association with MS. Variant chemokine expression could diminish or enhance the inflammatory response characteristic of MS. The majority of CC chemokine genes are located in a chromosomal region $(17 \mathrm{q} 11.2-12)$ that has shown suggestive linkage and association with MS in a number of genome wide screens [29-34]. Most recently, in a large genome wide linkage screen, no genome-wide significant results could be identified beyond the MHC [60]. However, suggestive linkage was identified on chromosome 17q23. An important deduction from this work was that linkage studies are under-powered to detect modest associations even in large cohorts.

We utilised a two-stage approach for this study, the first of which was sequencing of four DNA pools, three composed of MS patients and one control DNA pool across the 17q11.2-12 CC chemokine gene cluster. This approach allowed estimation of MAF for all common (MAF >0.15) SNPs across the CC chemokine genes in our Australian Caucasian cohort, and identification of two novel SNPs. This technique has been validated by our group [61]. Twelve SNPs were chosen for further analysis by individual genotyping, based on their likely functional significance (codon changing, location in the putative promoter region), prevalence ( $\mathrm{MAF}>0.1$ ), and/or uneven representation between the MS and control pools.
Overall, a large amount of genetic data has been gathered from pooled DNA sequencing and individual genotyping. The pooled sequencing provided a close estimate of MAF for SNPs across the $17 \mathrm{q}$ chemokine gene region, and verified the existence of common SNPs published in online databases. The individual genotyping data from 350-650 unaffected parents allowed the determination of MAF for the 12 SNPs chosen for further study, establishment of LD structure across the region, and calculation of haplotype frequencies in our unaffected Australian cohort. The MAF data facilitate power calculations for additional diseasesusceptibility studies, and it and the haplotype data should prove useful in studies of population variation for these immunologically important genes. From individual genotyping, MAF were established for the 12 markers in a large unaffected cohort (up to 600 unaffected parents), whilst $\mathrm{LD}$ analysis revealed the haplotype block structure across the cluster, and haplotype frequencies were also established.

Measurement of transmission distortion for each of the 12 SNPs in MS trios provided some evidence for over-transmission of several of the SNPs after stratification, but these trends would not survive a conservative correction for multiple comparisons.

The CCL5 -471C>T SNP, which we found might be associated with MS in HLA-DRB1*1501 negative patients, is of potential functional relevance, as it creates a new tran- 
Table 4: Haplotype TDT of CC chemokine gene cluster SNPs.

\begin{tabular}{|c|c|c|c|c|c|}
\hline Haplotype & Frequency & Transmitted & Non-transmitted & $\chi^{2}(\mathrm{Idf})$ & $P$ (uncorrected) \\
\hline \multicolumn{6}{|c|}{ (a) Local cohort } \\
\hline \multicolumn{6}{|c|}{ 5' haplotype block } \\
\hline \multicolumn{6}{|c|}{ 4-marker haplotypes } \\
\hline \multicolumn{6}{|c|}{ CCL2 -258I.CCL2 -2138.CCLI I -488.CCLI I $67(n=162$ trio families) } \\
\hline A.A.C.G & 0.33 & 57.0 & 85.0 & 5.50 & 0.02 \\
\hline A.T.C.G & 0.18 & 61.0 & 40.0 & 4.36 & 0.04 \\
\hline \multicolumn{6}{|c|}{ 3-marker haplotypes } \\
\hline \multicolumn{6}{|c|}{ CCL2 -258I.CCL2 -2138.CCLII -488 ( $n=162$ trio families) } \\
\hline A.A.C & 0.33 & 56.0 & 86.0 & 6.33 & 0.01 \\
\hline A.T.C & 0.18 & 61.0 & 40.0 & 4.36 & 0.04 \\
\hline \multicolumn{6}{|c|}{ CCL2 -2138.CCLI/ -488.CCLI/ 67 ( $n=162$ trio families) } \\
\hline A.C.G & 0.63 & 70.1 & 92.0 & 2.96 & 0.09 \\
\hline T.C.G & 0.18 & 60.9 & 40.0 & 4.34 & 0.04 \\
\hline \multicolumn{6}{|c|}{ 2-marker haplotypes } \\
\hline \multicolumn{6}{|c|}{ CCL2 -258I.CCL2 -2138 ( $n=204$ trio families) } \\
\hline A.A & 0.52 & 89.1 & 117.1 & 3.80 & 0.05 \\
\hline \multicolumn{6}{|c|}{ CCL2 $-2138 . C C L / \mid-488(n=162$ trio families) } \\
\hline A.C & 0.62 & 69.2 & 93.1 & 3.50 & 0.06 \\
\hline T.C & 0.18 & 60.8 & 39.9 & 4.32 & 0.04 \\
\hline
\end{tabular}

(b) Independent cohort $(n=169$ trio families)CCL2 $-2138 . C C L I /-488$

\begin{tabular}{|c|c|c|c|c|c|}
\hline A.C & 0.63 & 75.1 & 86.0 & 0.74 & 0.4 \\
\hline T.C & 0.20 & 59.9 & 52.0 & 0.56 & 0.5 \\
\hline \multicolumn{6}{|c|}{ (c) Combined dataset ( $\mathrm{n}=33 \mathrm{I}$ trio families) CCL2 $-2 \mid 38 . C C L I /-488$} \\
\hline A.C & 0.62 & 144.4 & 179.1 & 3.73 & 0.05 \\
\hline T.C & 0.19 & 120.6 & 91.9 & 3.89 & 0.05 \\
\hline
\end{tabular}

scription factor binding site [41], and has shown associations with atopic dermatitis, atopy and asthma [41,42]. CCL5 is an important inflammatory chemokine, with a range of activities upon eosinophils [62], monocytes and activated T cells $[63,64]$, and has been identified repeatedly in the CNS and CSF of MS patients [19,21,22]. Our data also identify CCL14 and CCL23 as warranting further investigation, with marginally significant (uncorrected) trends towards transmission distortion found in RR-MS and SP-MS patients for CCL14-649T>A, and in males for CCL23-289A>C. Little is known for either of these chemokines, beyond basic functionality, and neither has been studied with regard to MS pathogenesis. The CCL23 289A $>$ C SNP was found to affect a potential SP-1 binding site using the TRANSFAC database [65].

Upon analysing for haplotype transmission distortion across the CC chemokine gene cluster, we found suggestive evidence for association of haplotypes encompassing CCL2 and CCL11 (Table 4), which lie within a haplotype block spanning $33.1 \mathrm{~kb}$. CCL2 has been implicated in MS pathogenesis. It is chemotactic for T cells and monocytes $[66,67]$, is important in the induction of inflammation in
EAE [13], has been identified in MS lesions [17-19], and in contrast to EAE studies has been associated with remission of MS [68].

Recently (and subsequent to the completion of our study), a similar study of polymorphisms across the CC chemokine gene cluster was conducted by Vyshkina et al [46]. In this study, 31 SNPs derived from online databases were selected for genotyping in a variety of individuals. The basis of selection of SNPs was not discussed. This is in contrast to our approach, in which an informed decision for SNP selection was based on several criteria, discussed above, with a particular focus on SNPs with potential functional consequences. The SNPs assayed by Vyshkina et al [46] were predominantly non-coding, with no SNPs from putative promoter regions. Fifteen SNPs overlapped with those identified in our pooled DNA sequencing. Two SNPs, both exonic, were individually genotyped in our study; the remainder did not pass the first stage. One exonic SNP was excluded as it was not common, whilst an exonic SNP in CCL4 was not analysed as this gene was excluded from our study. Similar to our study, Vyshkina et al [46] found no strong evidence for association with any 
single locus. In addition, we identified similar LD structure surrounding CCL2.CCL11 and between CCL14 and CCL23, and identified haplotypic associations for the CCL2.CCL11 haplotype block. Whilst the SNPs analysed in this block were different between the two studies, it might be assumed that they are subject to the LD within the block. Thus, whilst we can not specifically say that we have replicated the haplotype associations of Vyshkina et al [46], we would suggest that the determination of haplotype tagging SNPs in this block is justified. It was interesting that our TDT analysis was conducted entirely in sporadic MS cases, whilst that of Vyshkina et al [46] had an emphasis on familial MS, yet both studies found weak association for the CCL2.CCL11 haplotype block with MS, suggestive of a general MS susceptibility factor within this block. This group has since verified their results in a second-phase study [69]. Thus, in a combined population totalling almost 1000 MS families (331 Australian; 644 North American), the results implicate a haplotype association encompassing the CCL2.CCL11 markers.

\section{Conclusion}

We have conducted a two-stage analysis of polymorphisms across the CC chemokine gene cluster. We identified novel SNPs in this region, and added further information to the data available on LD structure and haplotypes across the cluster. Interestingly, our best single-locus findings were for promoter SNPs (CCL5 471C>T, CCL14 -649T>A, CCL23 -289A>C), which might affect the relative expression of these chemokines and lead to downstream effects on leukocyte migration to the CNS, and therefore influence MS pathogenesis. We also confirmed the potential presence of a haplotypic association across CCL2 and CCL11. Further validation of the association of these SNPs in independent cohorts, and confirmation of their functional significance would support therapeutic targetting of these chemokines and their receptors.

\section{Competing interests}

The author(s) declare that they have no competing interests.

\section{Authors' contributions}

MJB was responsible for the conception of the project, acquisition and analysis of the data, interpretation of results and writing of the manuscript. $\mathrm{DB}, \mathrm{BB}$ and $\mathrm{GS}$ were responsible for the conception and design of the project, intellectual input, interpretation of results, and helped to draft the manuscript. RH was responsible for the clinical aspects of this project, including the assessment of MS patients. All authors read and approved the final manuscript.

\section{Additional material}

\section{Additional File 1}

Primers for the amplification of CC chemokine genes. This table presents the list of all primers used for pooled DNA sequencing.

Click here for file

[http://www.biomedcentral.com/content/supplementary/1471-

2350-7-64-S1.doc]

\section{Additional File 3}

Conditions for seven SNPs genotyped by SNaPshot. This table describes the oligonucleotides used for the SNaPshot genotyping, including reaction conditions.

Click here for file

[http://www.biomedcentral.com/content/supplementary/14712350-7-64-S3.doc]

\section{Additional File 2}

Summary of SNPs identified and analysed by sequencing of CC chemokine genes in DNA pools. This table is an extended version of Table 1, which describes the minor allele frequency and estimated relative risk data for all SNPs identified by pooled DNA sequencing.

Click here for file

[http://www.biomedcentral.com/content/supplementary/14712350-7-64-S2.doc]

\section{Acknowledgements}

The authors would like to thank the members of the Southern MS Genetics Consortium: Justin Rubio, Trevor Kilpatrick, Helmut Butzkueven, Niall Tubridy, Mark Mariott, Caron Chapman, John Carey, Jo Baker, Laura Johnson, Rachel Tan, Simon Foote, Stewart Huxtable, Melanie Bahlo, Jim Stankovich, and Terry Speed, Najwa Marmash for technical assistance, Susan Adams for recruitment of MS trio patients, Rex Simmons for providing familial MS cases, Vanessa Perich, Maria Ban, Natalie Hartley and Suzy Teutsch for preparation of the DNA samples, Mark Wheeler and llya Henner for running samples for sequencing and SNaPshot analysis, and Mike Payne for overseeing the genotyping of our samples by SNPlex ${ }^{\mathrm{TM}}$. This work was supported by a grant from the National Health and Medical Research Council of Australia (grant no. 153990). M.B. is the recipient of an Australian Postgraduate Award Scholarship and additional support was provided by Biogen Australia.

\section{References}

I. Ewing C, Bernard CC: Insights into the aetiology and pathogenesis of multiple sclerosis. Immunol Cell Biol 1998, 76(I):47-54.

2. Dyment DA, Sadovnick AD, Ebers GC, Sadnovich AD: Genetics of multiple sclerosis. Hum Mol Genet 1997, 6(10): 1693-1698.

3. Sawcer S, Compston A: The Genetic Analysis of Multiple sclerosis in EuropeanS: concepts and design. J Neuroimmunol 2003, 143(I-2): 13-16.

4. Stewart GJ: Multiple sclerosis, multiple genes. Medical Journal of Australia 1997, 166:573-574.

5. Brown KD, Zurawski SM, Mosmann TR, Zurawski G: A family of small inducible proteins secreted by leukocytes are members of a new superfamily that includes leukocyte and fibroblast-derived inflammatory agents, growth factors, and indicators of various activation processes. J Immunol 1989, I 42(2):679-687.

6. Baggiolini M: Chemokines and leukocyte traffic. Nature 1998, 392(6676):565-568.

7. Gale LM, McColl SR: Chemokines: extracellular messengers for all occasions? Bioessays 1999, 21(1):17-28. 
8. Karpus WJ, Lukacs NW, Kennedy KJ, Smith WS, Hurst SD, Barrett TA: Differential CC chemokine-induced enhancement of $T$ helper cell cytokine production. J Immunol 1997, I 58(9):4|29-4|36.

9. Taub DD, Turcovski-Corrales SM, Key ML, Longo DL, Murphy WJ: Chemokines and T lymphocyte activation: I. Beta chemok ines costimulate human $\mathrm{T}$ lymphocyte activation in vitro. Immunol 1996, I56(6):2095-2103.

10. Molon B, Gri G, Bettella M, Gomez-Mouton C, Lanzavecchia A, Martinez AC, Manes S, Viola A: T cell costimulation by chemokine receptors. Nat Immunol 2005, 6(5):465-47I.

II. Cappello P, Caorsi C, Bosticardo M, De Angelis S, Novelli F, Forni G, Giovarelli M: CCLI6/LEC powerfully triggers effector and antigen-presenting functions of macrophages and enhances T cell cytotoxicity. J Leukoc Biol 2004, 75(I): / 35- I42.

12. Taub DD, Sayers TJ, Carter CR, Ortaldo JR: Alpha and beta chemokines induce NK cell migration and enhance NK-mediated cytolysis. J Immunol 1995, I55(8):3877-3888.

13. Huang DR, Wang J, Kivisakk P, Rollins BJ, Ransohoff RM: Absence of monocyte chemoattractant protein $I$ in mice leads to decreased local macrophage recruitment and antigen-specific $\mathbf{T}$ helper cell type $I$ immune response in experimental autoimmune encephalomyelitis. I Exp Med 200I, 193(6):7|3-726

14. Karpus WJ, Lukacs NW, McRae BL, Strieter RM, Kunkel SL, Miller SD: An important role for the chemokine macrophage inflammatory protein-I alpha in the pathogenesis of the $T$ cellmediated autoimmune disease, experimental autoimmune encephalomyelitis. J Immunol I995, I55(1 0):5003-50I0.

15. Miyagishi R, Kikuchi S, Takayama C, Inoue Y, Tashiro K: Identification of cell types producing RANTES, MIP-I alpha and MIP. I beta in rat experimental autoimmune encephalomyelitis by in situ hybridization. J Neuroimmunol 1997, 77(1):17-26.

16. Tran EH, Kuziel WA, Owens T: Induction of experimental autoimmune encephalomyelitis in C57BL/6 mice deficient in either the chemokine macrophage inflammatory proteinIalpha or its CCR5 receptor. Eur I Immunol 2000, 30(5): $14|0-14| 5$.

17. McManus C, Berman JW, Brett FM, Staunton H, Farrell M, Brosnan CF: MCP-I, MCP-2 and MCP-3 expression in multiple sclerosis lesions: an immunohistochemical and in situ hybridization study. I Neuroimmunol I998, 86( I):20-29.

18. Van Der Voorn P, Tekstra J, Beelen RH, Tensen CP, Van Der Valk P, De Groot C]: Expression of MCP-I by reactive astrocytes in demyelinating multiple sclerosis lesions. Am J Pathol 1999, I 54(I):45-5I.

19. Simpson JE, Newcombe J, Cuzner ML, Woodroofe MN: Expression of monocyte chemoattractant protein-I and other betachemokines by resident glia and inflammatory cells in multiple sclerosis lesions. J Neuroimmunol 1998, 84(2):238-249.

20. Simpson J, Rezaie P, Newcombe J, Cuzner ML, Male D, Woodroofe $M N$ : Expression of the beta-chemokine receptors CCR2, CCR3 and CCR5 in multiple sclerosis central nervous system tissue. J Neuroimmunol 2000, 108(I-2): 192-200.

21. Hvas J, McLean C, Justesen J, Kannourakis G, Steinman L, Oksenberg $J R$, Bernard CC: Perivascular T cells express the pro-inflammatory chemokine RANTES mRNA in multiple sclerosis lesions. Scand J Immunol I997, 46(2): 1 95-203.

22. Sorensen TL, Tani M, Jensen J, Pierce V, Lucchinetti C, Folcik VA, Qin S, Rottman J, Sellebjerg F, Strieter RM, et al:: Expression of specific chemokines and chemokine receptors in the central nervous system of multiple sclerosis patients. J Clin Invest 1999, 103(6):807-815.

23. Sorensen TL, Sellebjerg F, Jensen CV, Strieter RM, Ransohoff RM: Chemokines CXCLIO and CCL2: differential involvement in intrathecal inflammation in multiple sclerosis. Eur J Neurol 200I, 8(6):665-672.

24. Strunk T, Bubel S, Mascher B, Schlenke P, Kirchner H, Wandinger KP: Increased numbers of CCR5+ interferon-gamma- and tumor necrosis factor-alpha-secreting $\mathbf{T}$ lymphocytes in multiple sclerosis patients. Ann Neurol 2000, 47(2):269-273.

25. Miyagishi R, Kikuchi S, Fukazawa T, Tashiro K: Macrophage inflammatory protein-I alpha in the cerebrospinal fluid of patients with multiple sclerosis and other inflammatory neurological diseases. J Neurol Sci 1995, I29(2):223-227.
26. Teleshova N, Pashenkov M, Huang YM, Soderstrom M, Kivisakk P, Kostulas V, Haglund M, Link H: Multiple sclerosis and optic neuritis: CCR5 and CXCR3 expressing T cells are augmented in blood and cerebrospinal fluid. I Neurol 2002, 249(6):723-729.

27. Mahad D, Callahan MK, Williams KA, Ubogu EE, Kivisakk P, Tucky B, Kidd G, Kingsbury GA, Chang A, Fox RJ, et al.: Modulating CCR2 and CCL2 at the blood-brain barrier: relevance for multiple sclerosis pathogenesis. Brain 2006, I 29(Pt I):2 I2-223.

28. Naruse K, Ueno M, Satoh T, Nomiyama H, Tei H, Takeda M, Ledbetter DH, Coillie EV, Opdenakker G, Gunge N, et al.: A YAC contig of the human CC chemokine genes clustered on chromosome I7qI I.2. Genomics 1996, 34(2):236-240.

29. Giedraitis V, Modin H, Callander M, Landtblom AM, Fossdal R, Stefansson K, Hillert J, Gulcher J: Genome-wide TDT analysis in a localized population with a high prevalence of multiple sclerosis indicates the importance of a region on chromosome I4q. Genes Immun 2003, 4(8):559-563.

30. Hensiek AE, Roxburgh R, Smilie B, Coraddu F, Akesson E, Holmans P, Sawcer SJ, Compston DA: Updated results of the United Kingdom linkage-based genome screen in multiple sclerosis. Neuroimmunol 2003, I 43(I-2):25-30.

31. Kuokkanen S, Gschwend M, Rioux JD, Daly MJ, Terwilliger JD, Tienari PJ, Wikstrom J, Palo J, Stein LD, Hudson TJ, et al.: Genomewide scan of multiple sclerosis in Finnish multiplex families. $\mathrm{Am} \mathrm{J}$ Hum Genet 1997, 6 I(6): I379-1387.

32. Sawcer S, Jones HB, Feakes R, Gray J, Smaldon N, Chataway J, Robertson N, Clayton D, Goodfellow PN, Compston A: A genome screen in multiple sclerosis reveals susceptibility loci on chromosome 6p2 I and I7q22. Nat Genet 1996, I3(4):464-468.

33. Sawcer S, Maranian M, Setakis E, Curwen V, Akesson E, Hensiek A, Coraddu F, Roxburgh R, Sawcer D, Gray J, et al:: A whole genome screen for linkage disequilibrium in multiple sclerosis confirms disease associations with regions previously linked to susceptibility. Brain 2002, I 25(Pt 6): $1337-1347$.

34. Dyment DA, Sadovnick AD, Willer C], Armstrong $H$, Cader ZM, Wiltshire S, Kalman B, Risch N, Ebers GC: An extended genome scan in $\mathbf{4 4 2}$ Canadian multiple sclerosis-affected sibships: a report from the Canadian Collaborative Study Group. Hum Mol Genet 2004, I 3(1 0): 1005-1015.

35. The Transatlantic Multiple Sclerosis Genetics Cooperative: A metaanalysis of genomic screens in multiple sclerosis. Mult Scler 200I, 7(I):3-II.

36. Jagodic M, Becanovic K, Sheng JR, Wu X, Backdahl L, Lorentzen JC, Wallstrom E, Olsson T: An advanced intercross line resolves eael8 into two narrow quantitative trait Loci syntenic to multiple sclerosis candidate Loci. J Immunol 2004, I73(2): 1366-1373.

37. Teuscher C, Butterfield RJ, Ma RZ, Zachary JF, Doerge RW, Blankenhorn EP: Sequence polymorphisms in the chemokines Scya I (TCA-3), Scya2 (monocyte chemoattractant protein (MCP)I), and Scyal 2 (MCP-5) are candidates for eae7, a locus controlling susceptibility to monophasic remitting/nonrelapsing experimental allergic encephalomyelitis. J Immunol 1999, 163(4):2262-2266

38. Jamieson SE, Miller EN, Black GF, Peacock CS, Cordell HJ, Howson JM, Shaw MA, Burgner D, Xu W, Lins-Lainson Z, et al.: Evidence for a cluster of genes on chromosome $|7 q| I-q 2 \mid$ controlling susceptibility to tuberculosis and leprosy in Brazilians. Genes Immun 2004, 5(I):46-57.

39. Modi WS, Goedert J], Strathdee S, Buchbinder S, Detels R, Donfield S, O'Brien SJ, Winkler C: MCP-I-MCP-3-Eotaxin gene cluster influences HIV-I transmission. Aids 2003, I 7( 16):2357-2365.

40. Gonzalez-Escribano MF, Torres B, Aguilar F, Rodriguez R, Garcia A, Valenzuela A, Nunez-Roldan A: MCP-I promoter polymorphism in spanish patients with rheumatoid arthritis. Hum Immunol 2003, 64(7):74I-744.

4I. Nickel RG, Casolaro V, Wahn U, Beyer K, Barnes KC, Plunkett BS, Freidhoff LR, Sengler C, Plitt JR, Schleimer RP, et al.: Atopic dermatitis is associated with a functional mutation in the promoter of the C-C chemokine RANTES. I Immunol 2000, 164(3): $1612-1616$

42. Fryer AA, Spiteri MA, Bianco A, Hepple M, Jones PW, Strange RC Makki R, Tavernier G, Smilie FI, Custovic A, et al.: The -403 G-->A promoter polymorphism in the RANTES gene is associated with atopy and asthma. Genes Immun 2000, I(8):509-5I4. 
43. Bennetts BH, Teutsch SM, Buhler MM, Heard RN, Stewart G]: The CCR5 deletion mutation fails to protect against multiple sclerosis. Hum Immunol I997, 58(I):52-59.

44. Barcellos LF, Schito AM, Rimmler JB, Vittinghoff E, Shih A, Lincoln R, Callier S, Elkins MK, Goodkin DE, Haines JL, et al.: CC-chemokine receptor 5 polymorphism and age of onset in familial multiple sclerosis. Multiple Sclerosis Genetics Group. Immunogenetics 2000, 5 I (4-5):28I-288.

45. Kantor R, Bakhanashvili M, Achiron A: A mutated CCR5 gene may have favorable prognostic implications in MS. Neurology 2003, $61(2): 238-240$.

46. Vyshkina T, Shugart YY, Birnbaum G, Leist TP, Kalman B: Association of haplotypes in the beta-chemokine locus with multiple sclerosis. Eur J Hum Genet 2005, I3(2):240-247.

47. Poser CM, Paty DW, Scheinberg L, McDonald WI, Davis FA, Ebers GC, Johnson KP, Sibley WA, Silberberg DH, Tourtellotte WW: New diagnostic criteria for multiple sclerosis: guidelines for research protocols. Ann Neurol 1983, I3(3):227-23I.

48. Lahiri DK, Nurnberger JI Jr: A rapid non-enzymatic method for the preparation of HMW DNA from blood for RFLP studies. Nucleic Acids Res 1991, 19(19):5444.

49. Teutsch SM, Booth DR, Bennetts BH, Heard RN, Stewart GJ: Identification of I I novel and common single nucleotide polymorphisms in the interleukin-7 receptor-alpha gene and their associations with multiple sclerosis. Eur J Hum Genet 2003, I I(7):509-5I5.

50. Ban M, Sawcer SJ, Heard RN, Bennetts BH, Adams S, Booth D, Perich $V$, Setakis $E$, Compston A, Stewart G]: A genome-wide screen for linkage disequilibrium in Australian HLA-DRBI*I50I positive multiple sclerosis patients. I Neuroimmunol 2003, I 43(I2):60-64.

5I. Norton N, Williams NM, Williams HJ, Spurlock G, Kirov G, Morris DW, Hoogendoorn B, Owen MJ, O'Donovan MC: Universal, robust, highly quantitative SNP allele frequency measurement in DNA pools. Hum Genet 2002, I I 0(5):47|-478.

52. den Dunnen JT, Antonarakis E: Nomenclature for the description of human sequence variations. Hum Genet 200I, 109:121-124.

53. Spielman RS, McGinnis RE, Ewens WJ: Transmission test for linkage disequilibrium: the insulin gene region and insulindependent diabetes mellitus (IDDM). Am J Hum Genet 1993, 52(3):506-5। 6.

54. Kruglyak L, Daly MJ, Reeve-Daly MP, Lander ES: Parametric and nonparametric linkage analysis: a unified multipoint approach. Am J Hum Genet 1996, 58(6): I347-1363.

55. Zhang K, Jin L: HaploBlockFinder: haplotype block analyses. Bioinformatics 2003, I9(10): |300-1301.

56. Clayton D: A generalization of the transmission/disequilibrium test for uncertain-haplotype transmission. Am J Hum Genet 1999, 65(4): I 170-1177.

57. Abecasis GR, Cherny SS, Cookson WO, Cardon LR: Merlin - rapid analysis of dense genetic maps using sparse gene flow trees. Nat Genet 2002, 30(I):97-I0I.

58. Altshuler D, Brooks LD, Chakravarti A, Collins FS, Daly MJ, Donnelly P: A haplotype map of the human genome. Nature 2005 437(7063): I299-I320.

59. Barrett JC, Fry B, Maller J, Daly MJ: Haploview: analysis and visualization of LD and haplotype maps. Bioinformatics 2005 2I(2):263-265.

60. Sawcer S, Ban M, Maranian M, Yeo TW, Compston A, Kirby A, Daly MJ, De Jager PL, Walsh E, Lander ES, et al.: A high-density screen for linkage in multiple sclerosis. Am J Hum Genet 2005, 77(3):454-467.

61. Bugeja MJ, Booth DR, Bennetts BH, Heard RNS, Stewart G]: An investigation of polymorphisms in the 4q13.3-2I.I CXC chemokine gene cluster for association with multiple sclerosis inAustralians. Mult Scler 2006 in press.

62. Kameyoshi Y, Dorschner A, Mallet Al, Christophers E, Schroder JM: Cytokine RANTES released by thrombin-stimulated platelets is a potent attractant for human eosinophils. J Exp Med 1992, $176(2): 587-592$.

63. Schall TJ: Biology of the RANTES/SIS cytokine family. Cytokine 1991, 3(3): 165-183.

64. Schall TJ, Bacon K, Toy KJ, Goeddel DV: Selective attraction of monocytes and $T$ lymphocytes of the memory phenotype by cytokine RANTES. Nature 1990, 347(6294):669-67|.
65. Wingender E, Chen X, Hehl R, Karas H, Liebich I, Matys V, Meinhardt T, Pruss M, Reuter I, Schacherer F: TRANSFAC: an integrated system for gene expression regulation. Nucleic Acids Res 2000 , 28(I):3|6-319.

66. Taub DD, Proost P, Murphy WJ, Anver M, Longo DL, van Damme J, Oppenheim J]: Monocyte chemotactic protein-I (MCP-I), -2, and $\mathbf{- 3}$ are chemotactic for human $\mathbf{T}$ lymphocytes. J Clin Invest 1995, 95(3): 1370-1376.

67. Loetscher P, Seitz M, Clark-Lewis I, Baggiolini M, Moser B: Monocyte chemotactic proteins MCP-I, MCP-2, and MCP-3 are major attractants for human CD4+ and CD8+ T lymphocytes. Faseb ] 1994, 8( I 3): 1055-1060.

68. Mahad DJ, Howell SJ, Woodroofe MN: Expression of chemokines in the CSF and correlation with clinical disease activity in patients with multiple sclerosis. J Neurol Neurosurg Psychiatry 2002, 72(4):498-502.

69. Vyshkina T, Kalman B: Haplotypes within genes of beta-chemokines in I7q I are associated with multiple sclerosis: a second phase study. Hum Genet 2005:I-9.

\section{Pre-publication history}

The pre-publication history for this paper can be accessed here:

\section{http://www.biomedcentral.com/1471-2350/7/64/prepub}

Publish with Biomed Central and every scientist can read your work free of charge

"BioMed Central will be the most significant development for disseminating the results of biomedical research in our lifetime. "

Sir Paul Nurse, Cancer Research UK

Your research papers will be:

- available free of charge to the entire biomedical community

- peer reviewed and published immediately upon acceptance

- cited in PubMed and archived on PubMed Central

- yours - you keep the copyright
BioMedcentral 